\title{
A BRINCADEIRA "FORA DE HORA": AFIRMAÇÃO, FRUIÇÃO E OS IMPASSES DA AÇÃO DE CRIANÇAS NA ESCOLA
}

Los juegos fuera de horario: afirmación, fruición y los impasses de la actitud de los niños en la escuela

Classroom misbehaviour: affirmation, enjoyment and the standoff of children's action at school

\section{Isa Kaplan Vieira}

PPGP - IP - UFRJ. Correo electrónico: i.kaplanvieira@gmail.com

\section{Lucia Rabello de Castro}

$$
\text { PPGP - IP - UFRJ. Correo electrónico: 1rcastro@infolink.com.br }
$$

\section{Resumo}

Se o controle e a colocação de normas por parte dos adultos hoje não se faz sem tensões e questionamentos, a ação de crianças é parte fundamental desta tensão. Pensamos aqui em ações através de um viés que não somente o de resposta ou provocação; a ação "fora de hora" (que escapa às regras, normas e demandas ou que incomoda, foge ao esperado) é ação expressiva, criativa e afirmativa, como apontado por Winnicott (1975), não necessariamente se colocando contra algo. Como parte do desenvolvimento empírico do trabalho, foram realizadas onze oficinas em três escolas no total - duas municipais e uma privada. As oficinas convidaram as crianças a fazerem desenhos sobre o que imaginavam da situação descrita pela frase, inspirada em alguns registros de ocorrência encontrados: "os alunos fizeram gracinhas e os outros riram". Além disso, foi feita uma de análise de registros de ocorrência referente a turmas destas séries. Os resultados mostraram que as brincadeiras em sala de aula ocupam lugar fundamental no cotidiano dos participantes, de maneira que a interação entre crianças é fundamentalmente perpassada por esta. Com a brincadeira, é possível serem co-criadoras neste espaço, recriando o espaço da sala de aula, os objetos e as relações nesta realidade escolar. Destaca-se, aqui, também, a concepção de Winnicott de que a ação criativa necessariamente afeta o ambiente, na medida em que envolve certa expansidade. Este afetamento leva a impasses que não podem ser controlados de antemão; fazem parte da 
complexa trama relacional do convívio na escola de maneira a serem acompanhados e elaborados permanentemente.

Palavras-chave: escola, brincadeira, ação.

\title{
Resumen
}

Si hoy el control y la colocación de normas por parte de los adultos no se hace sin tensiones y cuestionamientos, la actitud de los niños es parte fundamental de esta tensión. Pensamos aquí en acciones a través de un sesgo que no es solamente una respuesta o una provocación; la acción fuera del horario (que escapa a las reglas, normas y demandas o que molesta, huye al esperado) es una acción expresiva, creativa y afirmativa, como apunta Winnicott (1975), no necesariamente colocándose en contra algo. Como parte del desarrollo empírico del trabajo, se realizaron once talleres en tres escuelas en total - dos municipales y una privada. Los talleres invitaban a los niños a hacer dibujos sobre lo que imaginaban frente a una situación descrita por una frase, que fue inspirada en algunos registros de ocurrencia encontrados: "algunos alumnos hicieron bromas y los otros se rieron". Además, se hizo un análisis de registros de ocurrencia referente a clases de estas series. Los resultados mostraron que los juegos en aula ocupan a un lugar fundamental en el cotidiano de los participantes, de manera que la interacción entre niños es fundamental pasar por ésta. Con el juego, es posible ser cocreadores en este espacio, re-creando el espacio de aula, los objetos y las relaciones en esta realidad escolar. Se destaca, aquí, también, la concepción de Winnicott, de que la acción creativa necesariamente afecta al ambiente, a medida en que implica cierta expansión. Esta actitud conlleva a impases que no pueden ser controlados de antemano; son parte de la compleja trama relacional de la convivencia en la escuela, de manera a ser acompañados y elaborados permanentemente.

Palabras clave: escuela, juego, acción.

\begin{abstract}
If the control and placement of norms by adults today is not done without tensions and questions, the action of children is a fundamental part of this tension. Here, we think of actions through a bias that not only the response or provocation; Classroom misbehavior (which escapes rules, norms and demands or that bothers, escapes expectations) is expressive, creative and affirmative action, as pointed out by Winnicott (1975), not
\end{abstract}


necessarily against something. As part of the empirical development of the work, eleven workshops were held in three schools in total - two municipal schools and a private one. The workshops invited the children to draw pictures of what they imagined from the situation described by the phrase, inspired by some records of occurrence found: "the students made fun and the others laughed." In addition, an analysis was conducted about the incident reports concerning the classes of these grades. The results showed that the classroom misbehavior have a fundamental place in the daily life of the participants, so that the interaction between children is fundamentally permeated by it. By messing around, it is possible to be co-creators in this space, re-creating classroom space, objects and relationships in this school reality. Here, too, we highlight Winnicott's conception that creative action necessarily affects the environment, insofar as it involves a certain expansion. This affectation leads to impasses that cannot be controlled beforehand; they are part of the complex relational network of the conviviality in the school in a way to be followed and elaborated permanently.

Keywords: school, misbehavior, action.

\section{Introdução}

A relação entre crianças e adultos é hoje perpassada cada vez mais pela reflexão e problematização acerca da questão da obediência. De um lado, adultos se indagam muito mais acerca de qual seria o lugar justo para o mando e o controle; de outro, crianças expressam contestações cada vez mais amparadas na direção de seus desejos e necessidades (Gullestad, 1996). Se o controle e a colocação de normas hoje não se faz sem tensões e questionamentos de ambos os lados, interessa refletir acerca da ação de crianças como parte fundamental desta tensão, expondo de diversas formas aquilo que é invisibilizado pelos adultos no contexto familiar ou escolar.

Como vemos em Renaut (2005), o controle pautado exclusivamente em bases tradicionais, naturalizadas, como na relação de autoridade de outrora, já não se sustenta ${ }^{1}$. Assim, partindo da compreensão de que se o sentido que crianças dão às regras, normas

\footnotetext{
${ }^{1}$ Entendendo que a noção de autoridade trata de legitimação de um lugar hierárquico - ou "acréscimo de poder", como diz ARENDT (1961), podemos dizer que a crise da autoridade educacional hoje com frequência expõe o poder sem tal acréscimo, já que carecendo de tal legitimação a priori tende a recair sobre o autoritarismo e mesmo à violência para garantir a manutenção de certas relações pautadas na hierarquia, quando não há legitimação.
} 
e imposições ainda é muito pouco escutado (Prout, 2000, Castro, 2012, Sultana, 1989) podemos entender que a falta de sentido ou discordância emergem trazendo frequentemente incômodos para ambos os lados. Interessa, neste sentido, observar a maneira que a criança é capaz, com suas ações, de catalisar incômodos e interpelar o educador acerca do controle que este exerce. Para Prout (2000), agência e vulnerabilidade coexistem: ao mesmo tempo que as crianças não estão livres da produção de seus corpos como vulneráveis, estão longe de se portarem de forma dócil diante das normas distribuídas; se engajam ativamente em negociar o sentido, resistir e modificar a implementação desta.

Embora, como todos os atores sociais, as crianças possam ser vistas como moldadas e limitadas pelas circunstâncias de suas vidas, elas podem também as moldar e são capacitadas por estas. Elas são limitadas pelas condições de suas vidas sociais, mas também encontram modos de conduzir criativamente, negociar e ampliar as possibilidades (Prout, 2000, p.7, tradução nossa)

Muitos apontam que a chamada indisciplina e a tensão entre crianças e adultos na escola representaria, frequentemente, uma maneira de responder a situações que crianças e jovens consideram injusta ou sem sentido (Guirado, 1996, Simpson 2000, Raby 2005, Aquino, 2005). Entendemos aqui que esta tensão deriva não apenas da situação hierárquica inerente a transmissão educacional, mas principalmente de tudo aquilo que excede, que é sentido como injusto, incoerente, inconsistente e/ou não baseado em uma lógica de reciprocidade. A escola pública no Brasil é espaço que educadores, em situação precarizada, não encontram tempo, espaço e disponibilidade interna para uma relação de maior cuidado. Entretanto, não é só na escola pública brasileira que se manifestam as desigualdades e injustiças na relação institucional e geracional. Ressaltamos, neste sentido, pesquisas que observam que frequentemente os alunos afirmam não ser contra a existência de regras escolares, considerando muitas delas importantes para o funcionamento da escola, mas que destacam a falta de sentido em algumas, tais como as de vestimenta e etiqueta (Devine, 2002; Castro et al, 2010, Thornberg, 2008). Podemos pensar que estas regras são sentidas por estes como tendo função de civilizar, adequar, normatizar e controlar mais do que cuidar e organizar o aprendizado. Ainda, repetidas vezes surge nas pesquisas com crianças e 
jovens o tema da reciprocidade; da percepção destes de que as regras e cuidados demandadas a eles não são compartilhadas pelos adultos.

Se a chamada indisciplina é associada muitas vezes a tal tensão da relação intergeracional, por outro lado, interessa aqui pensar nas ações "fora de hora" - ações que escapam às regras, normas e demandas ou que incomodam, fogem ao esperado por um viés que não somente o de resposta, provocação, contraposição. Acompanhando as observações de Winnicott (1975) compreendemos que a ação "fora de hora" não necessariamente é vivenciada como oposição mas é também ação expressiva e afirmativa, pautada na fruição e na criatividade. Para Winnicott, a criatividade está ligada à capacidade de desfrutar de si mesmo; à sensação de ser real e estar vivo e neste sentido poder ter ação espontânea no meio. É por meio da criatividade que a criança se apropria dos objetos do mundo e é por este meio que ela atesta a estabilidade dos objetos e de si mesma. Assim, se sente capaz de co-criar a realidade. Não se trata, portanto, de uma produção original, artística, como no uso comum do termo, mas da sensação de realidade na experiência dos objetos e, consequentemente, da crença na possibilidade de reinvenção do ambiente (Winnicott, 1975).

Parece interessante observar que o sentido que os alunos atribuem para o estar na escola hoje é distribuído de formas distintas diante da identificação com aquilo que é demandado e esperado, assim como diante da esperança de que existam recompensas que fazem valer a pena o longo investimento na escola. Entretanto, ressaltamos que tanto os que se identificam quanto os que não se identificam com o projeto escolar encontram frequentemente outras identificações e sentidos na escola. Destaca-se aqui a maneira como são perpassados neste espaço a relação com os pares, a amizade, a sociabilidade e a diversão (Castro et al, 2010). Assim, entendemos que a brincadeira "fora de hora" é parte da construção permanente de sentidos não-oficiais que compõem - de forma tão presente, mas nem sempre visível e legitimada - o espaço escolar. Se as crianças relatam muitas vezes encontrar sentido na escola a partir da relação entre pares, podemos entender que as ações que fogem ao controle dos adultos se dão também no sentido da afirmação de desejos e interesses que se constroem no âmbito destas relações, espaço em que a criatividade pode se dar, na medida em que não se encerra na esfera intrapsíquica, mas envolve necessariamente o outro. 
É interessante pensar também na contribuição de Winnicott no que se refere à agressividade e sua relação com a criatividade. Para ele, os impulsos de agressão seriam inerentes à constituição do ser humano (1999) e não se dariam com intenção de destruição; a agressividade seria uma propriedade do corpo, da própria manifestação da vida biológica. Neste sentido, o impulso agressivo seria essencial para a construção de uma constância do objeto - quando o objeto "sobrevive à destruição" o sujeito sente que "pode usá-lo", ou seja, pode relacionar-se de forma criativa, espontânea, expansiva. Segundo Winnicott, quando a palavra 'fazer' pode ser usada com propriedade, já existe a criatividade (Birman, 2008); e a ação criativa necessariamente afeta o ambiente a partir da expansividade que lhe é inerente.

A ideia de "brincadeira fora de hora" remete a uma fala comum no ambiente escolar, ambiente perpassado pela lógica da produtividade e divisão do tempo, em que a hora de brincar quase sempre se restringe ao recreio. O aspecto de positividade das ações que estão fora do esperado é trazido aqui de forma a ampliar o olhar e aprofundar, em uma pesquisa empírica, compreensões sobre a vivência da criança na escola. Parece importante observar sobre a maneira que tais ações expressivas de crianças são encaradas neste ambiente assim como, principalmente, compreender como são encabeçadas e vivenciadas pelas mesmas, que sentidos e afetos as acompanham. Entende-se que esta vivência é perpassada pela relação com os educadores, com a instituição e com esferas mais amplas, mas também por aspectos menos visíveis aos adultos ligados à relação entre pares.

\section{Encaminhamentos metodológicos e análise do campo empírico}

Para uma aproximação do objetivo mencionado acima, foi realizada uma pesquisa empírica com crianças de $1^{\circ}$ a $6^{\circ}$ ano $\left(1^{\circ}\right.$ segmento do Ensino Fundamental) em quatro escolas: A. e B., escolas municipais, C., estadual e D., privada. São escolas de realidades sociais e econômicas bastante distintas, localizadas nas proximidades do Centro e Zona Sul do Rio de Janeiro. A pesquisa foi pensada e realizada em duas etapas: uma de análise de registros de ocorrência referentes a alunos e turmas destas séries, das quais participaram as quatro escolas; e outra que contou com onze oficinas em turmas deste segmento, etapa em que fizeram parte somente as escolas A., B. e D. 
Além disso, foram analisadas conversas informais que ocorreram com os professores principalmente na escola B.

Registros de ocorrência são cadernos ou folhas, em geral (no caso da escola D., de um programa no computador) em que educadores registram tudo aquilo que acontece no meio escolar que foge ao esperado; geralmente se trata de comportamentos dos alunos (em que algumas vezes os pais e/ou a criança serão notificados) mas em alguns casos também são registrados pequenos acidentes, doenças que se apresentam na escola etc. Foram encontrados 285 registros no total. Os registros variam um pouco em relação às séries que abarcam, mas todos estão dentro do intervalo do $1^{\circ}$ ao $6^{\circ}$ ano. Quanto às oficinas as turmas em cada oficina contavam em média com cerca de 25 crianças, somando-se portanto cerca de 270 crianças envolvidas nesta etapa.

As oficinas consistiram em encontros únicos com cada turma, em que se apresentava a proposta de que realizassem um desenho coletivo (em grupos de 3 a 5 crianças) para expressar sua própria visão e assim ajudar na compreensão da frase contida em um caderno de registro "Os alunos fizeram gracinhas e a turma inteira gostou”. Esta frase, inspirada em duas ocorrências encontradas na primeira etapa que traziam a expressão "gracinha" ${ }^{2}$ foi escolhida para ser usada como dispositivo disparador em todas as oficinas por sua referência a brincadeira e o humor em seus sentidos mais amplos. Nas oficinas, o tema da brincadeira foi acessado tanto nas enunciações e expressões deles feitas no âmbito das demandas da oficina quanto na observação das crianças no momento da oficina. O registro foi feito em gravador e em anotações.

\section{Análise e discussão dos resultados}

Alguns exemplos de ações registradas nos cadernos se destacaram expondo um contexto de muita interação e diversidade de brincadeiras em sala de aula. Cantar e dançar, fazer piadas, fazer guerra de batom, de cola e de bolinha de papel, empurrar a mesa para espremer os demais, jogar bolinha de gude em sala de aula, fazer apelos sexuais aos colegas, apertar as partes intimas do amigo, abaixar a bermuda dos colegas e correr

\footnotetext{
${ }^{2}$ São estas : "O aluno T., em meio às atividades começou a cantar e dançar. Pedi que o mesmo parasse e concluisse as tarefas. $\mathrm{O}$ aluno continuou com gracinha ao ser mais uma vez repreendido falou que a turma gostou e eu não gostei. O problema é meu e quem manda na boca dele é ele. $\mathrm{O}$ aluno foi advertido oralmente." e "Gracinhas, piadas, ficaram rindo sem parar na aula de artes".
} 
atrás dos colegas com tesoura e com lupa foram algumas das descrições encontradas. Apesar de existirem relatos de ações realizadas por só uma criança ou compartilhadas de forma mais discreta por um pequeno grupo, vemos nestes registros diversos casos em que a ação envolve muitos alunos ou ao menos parece envolver certa reverberação que engloba uma parte maior da turma. Os registros que fazem menção a atrapalhar a aula ou a risadas parecem ser um exemplo disso; os relatos frequentes de guerras de bolinha de papel e outros objetos (cadeiras, livros, colas, bolinhas de gude), por exemplo, retratam claramente os aspectos da interação entre um maior número de crianças.

Quanto às oficinas, o processo de realização da tarefa proposta em geral se deu de maneira dispersa e agitada: muitas brincadeiras, bagunça, barulho, movimentação pela sala, longas discussões sobre a tarefa nos grupos (dificuldade de chegarem a acordos) e intensa interação física entre as crianças (cutucadas com vassoura, “gravatas", tapas, beliscões, empurrões, puxões de cabelo, corre-corre, derrubar cadeiras etc.). Diante do tempo de duração da oficina (em média aproximadamente 50 minutos), grande parte dos desenhos não foi terminada. Porém, foi possível uma aproximação dos sentidos dados a estes pelas crianças que o fizeram. Foi possível, também, o registro das ideias levantadas por eles e modificadas posteriormente.

De forma geral, nas oficinas, foi central observar que a presença da pesquisadora como única adulta em sala de aula acabou possibilitando um afrouxamento do controle cotidiano e assim o emergir de múltiplas brincadeiras e ações "de escape" em geral. As ações das crianças se davam de forma muitas vezes completamente independente das demandas feitas pela pesquisadora e dificultavam o prosseguimento da atividade da maneira esperada, modificando seu formato, seu tempo, seu resultado. Um exemplo disso foi a frequente impossibilidade de terminarem os desenhos e de efetivar-se uma discussão geral no final da atividade. Este e outros aspectos centrais observados nas oficinas foram analisados tendo em vista também a fala das crianças sobre seus próprios desenhos e sobre a temática trazida na oficina, como veremos a seguir.

3.1. Aspectos do brincar em sala de aula: interação, criatividade, afirmação e fruição 
Tanto nas brincadeiras que se deram na oficina quanto nas retratadas nos desenhos, pudemos encontrar interações que categorizamos como físicas e humorísticas ${ }^{3}$. As brincadeiras que envolvem predominantemente o contato físico se fizeram presentes em todas as oficinas e incluíam empurrões, correrias, beliscões, tapas etc. expondo por vezes fronteira sutil entre essas e as brigas. Nos desenhos, as interações físicas aparecem muito frequentemente através da ideia da guerra de bolinha, de papel e de aviãozinho, desenhos que contém bastante movimento e vivacidade em geral. Ressaltase também, como mencionado acima, que nos registros de ocorrência analisados há muitos relatos destas guerrinhas, ocorrendo com diversos objetos como cola, batom, livros etc. Já as interações marcadas pelos aspectos humorísticos incluíam piadas, provocações, charadas etc. observadas tanto no momento das oficinas quanto nos desenhos.

Como será tratado, estas situações por vezes se apresentavam de forma tranquila e prazerosa e outras vezes incluíam ofensas, provocações e também incômodos com a bagunça. Tanto as interações humorísticas quanto as físicas eram expressadas com nuances e complexidades: ora como um regozijo coletivo, ora de forma mais contida, com pequenos grupos e duplas. Por vezes, se dava também o destaque de algumas crianças, desenhadas e mencionadas como palhaços.

Podemos entender que estas brincadeiras se dão em uma rede de interações que não se mostra restrita às amizades, mas que também não parece conectar de forma homogênea a todos na turma, como aponta Salgado (2010). Neste sentido, foi possível presenciar algumas falas que indicam que a risada circularia apenas entre aqueles que sentem-se enturmados, como a trazida abaixo.

Em outro grupo de que me aproximo pergunto: ["O que vocês estão desenhando?"] "Os garotos sentados na cadeira..." ["Como vocês acham que a turma reage nessa situação?... Como vocês imaginam?.."] “Todo mundo ri..." [ "Todo mundo?"] "A maioria. Todo mundo menos F e L. E G..... Mentira, só G. Mesmo...! Porque ele entrou esse ano, ainda não está enturmado, então fica sério”.'(Trecho do diário de campo)

\footnotetext{
${ }^{3}$ Estas categorias não se dão de forma estanque, marcando ações completamente distintas, mas apontam para aspectos diferentes das ações.
} 
Entretanto, como dito, brincadeiras que envolviam um número maior de crianças foram também apresentadas, o que possibilita que se compreenda que existe nestas brincadeiras mesmo que de forma pontual e incipiente um sentido que envolve muitos alunos - risos, olhares, "chamar a atenção", como relatado pelos educadores nos cadernos de registro.

Um exemplo de brincadeira que envolve um maior número de crianças é a do "urro", exposta na Imagem 1: as crianças explicam que é uma referência ao filme Shreck e que a turma desenvolveu espontaneamente a brincadeira de, quando um grita "faz o urro" outros respondem com o tal urro, reverberando com diversas crianças da turma ao mesmo tempo.

O outro grupo me explica que estão fazendo o urro, me explicam que é algo que muitos fazem e que é do filme do shreck, que ele faz o urro... "Então alguém da turma puxa "faz o urro!" e todos fazem.." Dois grupos acabam fazendo a mesma coisa mesmo sem se comunicar, me explica. Pergunto se é algo da turma ou da escola ou geral, eles respondem que muita gente faz isso. (Trecho do diário de campo)

De forma semelhante vemos a brincadeira de "Ship", que seria uma brincadeira que perpassaria mais de uma turma da mesma escola. O "Ship" ${ }^{4}$, relatado na escola D., é uma brincadeira de origem midiática, bastante utilizada por adolescentes e em referência a pessoas famosas que consiste em juntar o nome de duas pessoas brincando que elas devem se relacionar, formar um casal. As crianças explicam que tentam juntar um casal e que a graça é envergonhar os alvos. É de forma leve, risonha, que um menino conta sobre ser vítima do "ship", a tal brincadeira de formar casais.

As formas de interação trazidas aqui se apresentam quase sempre em associação àquilo que denominam bagunça, ligada nas falas especialmente ao corre-corre e ao barulho, que dificultam o professor de dar aula. Como exemplo disso, vemos que em uma turma, quando se repetiu o enunciado acerca da gracinha, um grupo perguntou, sorridente "Então você está falando de quando a gente faz bagunça" e "ah tia,

${ }^{4}$ Ship é um termo originado do sufixo das palavras inglesas friendship e relationship (amizade e relacionamento) 
bagunça é tipo quando a professora sai de sala e a gente belisca, empurra, derruba”, associação que se fez presente também em diversos outros momentos. É o caso, também, de um menino que interrompe as anotações da pesquisadora e pergunta o que ela está anotando, com uma espécie de preocupação ou curiosidade. Perguntado o que ele imaginaria que estaria sendo anotado, ele responde, rindo: "a turma tá a maior bagunça!!!!"”

Ressalta-se, assim, de maneira central, a maneira como os elementos de prazer e diversão se faziam bastante presentes nos desenhos feitos pelas crianças e em suas colocações no momento da oficina, como vemos no trecho abaixo. Isso fica claro também na maneira que estas mencionam frequentemente o tema sem disfarces ou constrangimentos, assim como pelo tom de voz e movimentos corporais.

[Pirraça, como assim?] "Bagunça, pra caramba!”, diz alegre e continua: "teve um dia que ele jogou uma fatia de bolo na cara dele, aí a gente pegou $m \& m$ e jogou e entrou aqui (mostra no nariz e no ouvido) aí jogou a corrente e começou a correr, aí a professora veio atrás..." [e aí?] "Ai a professora pediu pra ir pra diretoria, ela tava nervosa... Foi o dia mais engraçado, ele soltou um peido na cara do... E o T. fez cocô na calça...”. (...). (Trecho do diário de campo)

As imagens de desenhos abaixo e a fala dos alunos acerca destes desenhos expõem outras situações em que os alunos trouxeram uma valorização da brincadeira "fora de hora", com elementos de diversão, interação e criatividade.

No desenho da imagem 2, abaixo, vemos um cenário que parece divertido e assustador: meninos fazendo malabarismos, um em cima do outro, outros que riem e exclamam: "meu deus!". Os meninos que fazem os malabares têm uma aparência diferente dos que assistem: olhos grandes e cabelos arrepiados. Explicam, na conversa, que são alunos vestidos de palhaços: "Ai tem um fazendo som de pum e o outro enfiando um lápis por um buraco do nariz e saindo pelo outro... Esse aqui é um palhaço assassino".

$\mathrm{Na}$ imagem 3, há diferentes elementos: um mural com os dizeres coloridos (incompleto) "como é linda a primavera", igual ao que consta na sala destas crianças; há um menino e uma menina lado a lado, um super-herói, nuvens, um pequeno carro e 
diversas crianças brincando com bolinhas coloridas. Estas acumulam uma pilha de bolinhas e dizem "Uh, esse nen vir (esse nem vi)/ olha o dindin, vou comprar bala / Quem jogou?/Eu, porque!’. As crianças explicam, na conversa, que dindin é dinheiro pra comprar bastante pirulito e não dividir com ninguém (riem). Sobre o super-herói, explicam que ele é preso pela polícia federal. Ainda, perguntam, no início, se poderiam desenhar uma guerra de sorvetes na escola. Parecem se divertir bastante enquanto desenham, como que delineando uma narrativa fantasiosa, em que cada um desenha uma parte, às vezes ao mesmo tempo. Já no desenho da Imagem 6 parece haver maior mistura e interação de elementos fantasiosos com objetos típicos de sala de aula: vemos crianças penduradas no quadro negro, fazendo piruetas e tocando instrumento ou cantando. Chama atenção a maneira como a criança senta no quadro e toca o instrumento, ao mesmo tempo que outra escreve "estudando coisas chatas"; utiliza assim um objeto típico de sala de aula, como o quadro negro, de forma distinta da usual.

Nas Imagens 4 e 5 ressaltamos a riqueza de elementos imaginativos e a maneira como são retratadas certas ações das crianças que afetariam bastante a todos ao redor. $\mathrm{Na}$ imagem 4, há os dizeres, do menino ao centro do desenho: "Se eu não passar apago a escola / Estou com estilingue hein”. Há cadeiras e um quadro negro no desenho, e o grupo conta que o garoto vai apagar a escola, como vemos no fragmento abaixo.

Ele diz que vai apagar a escola com o apagador, vai pegar o apagador e ameaçar apagar se não tirar 10 nas provas" [e depois?] "aí ele fala que vai apagar todo mundo só que não acontece nada". Outro menino me mostra tocando a borracha, e eu pergunto: [é borracha ou apagador?] "é ... Tanto faz... É a mesma coisa...” [e isso acontece com vocês?...] "quase todo recreio a gente invade a sala" [invade a sala?...] "nos recreios a gente entra aqui escondido na sala fica fazendo parkour" [porque na sala e não no pátio?] "porque a gente faz parkour nas cadeiras a gente pula nas cadeiras". (Trecho do diário de campo)

Mais uma vez, no desenho da Imagem 5, há uma profusão de elementos fantasiosos que indicariam prazer. São árvores com frutos infinitos, super-heróis que têm super poderes e raios, anjos e vilões. Este cenário é trazido com bastante cor e 
movimento no desenho e com bastante animação. Os raios aparecem como um "super poder" (nas palavras das crianças), ligado à diversão e, podemos pensar, a status elevado (como super-heróis). Neste caso, não podemos ter clareza do efeito que os raios possuem sobre os outros; se é algo violento e/ou uma forma de atingi-los com humor, por exemplo. De qualquer forma, importa ressaltar que a maneira como demonstram afetar a todos ao redor é trazida com regozijo.

(...) Passando novamente nos grupos vejo que o grupo quatro está desenhando animado e coletivamente. Parece não haver mais briga depois que J. foi para outro grupo. Eles estão desenhando algo bastante animados e eu pergunto o que é, eles me dizem que são super-heróis e raios. Eu pergunto se eles estão sendo atingidos ou se eles lançam raios e eles me dizem que eles lançam raios [em quem?] "em todos" [na professora e nos outros alunos?] "sim, todos"). Me mostram também uma árvore com uvas e morangos que seriam infinitos. Eu pergunto então se os super-heróis são meninos que estão fazendo gracinhas (como no enunciado da proposta), eles dizem que sim, que aqueles que bagunçam estão lançando raios a todos da turma, a todo mundo. Pergunto como fica a turma com essa bagunça e eles dizem que todo mundo ama eles porque eles têm super poderes. (...) Em algum momento pergunto quem é quem exatamente no desenho pois ainda estou em dúvida (são vários voando); eles dizem que tem um super herói, um super vilão, anjos e Jesus Cristo que estão lá para que eles entrem e saiam bem da escola. (Trecho do diário de campo) 


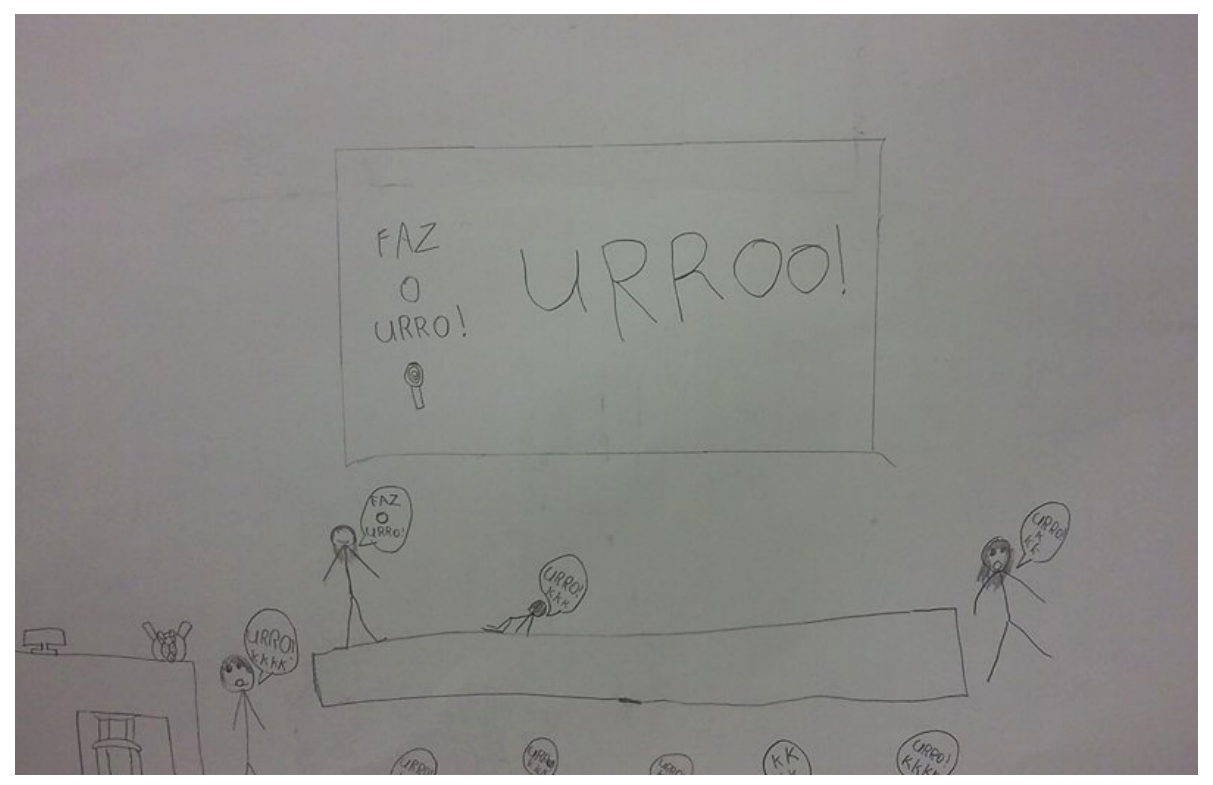

Imagem 1 - "Faz o urro"

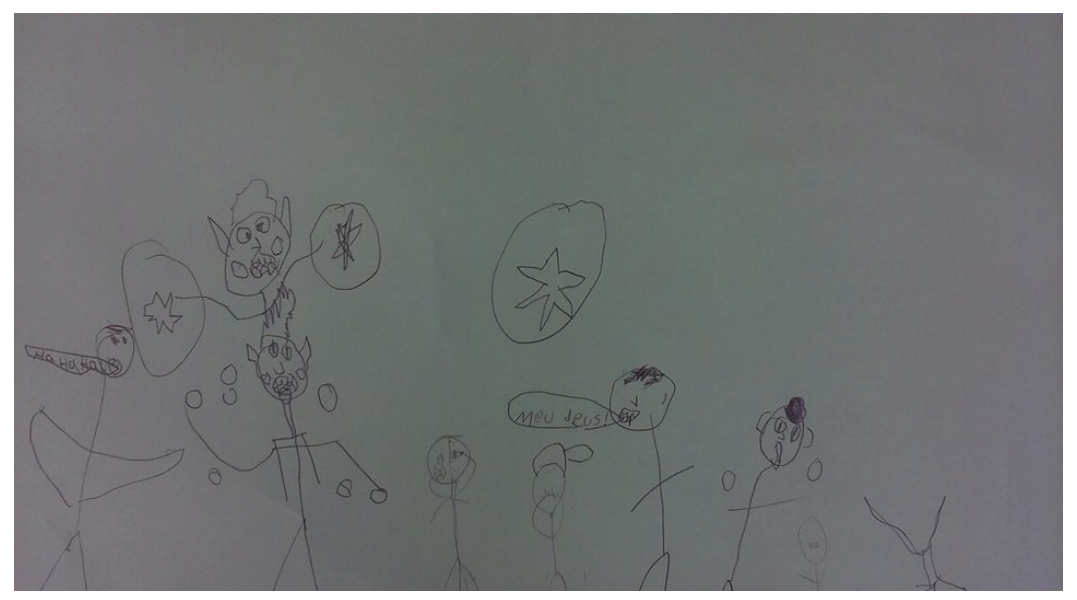

Imagem 2 - "meus deus !" 


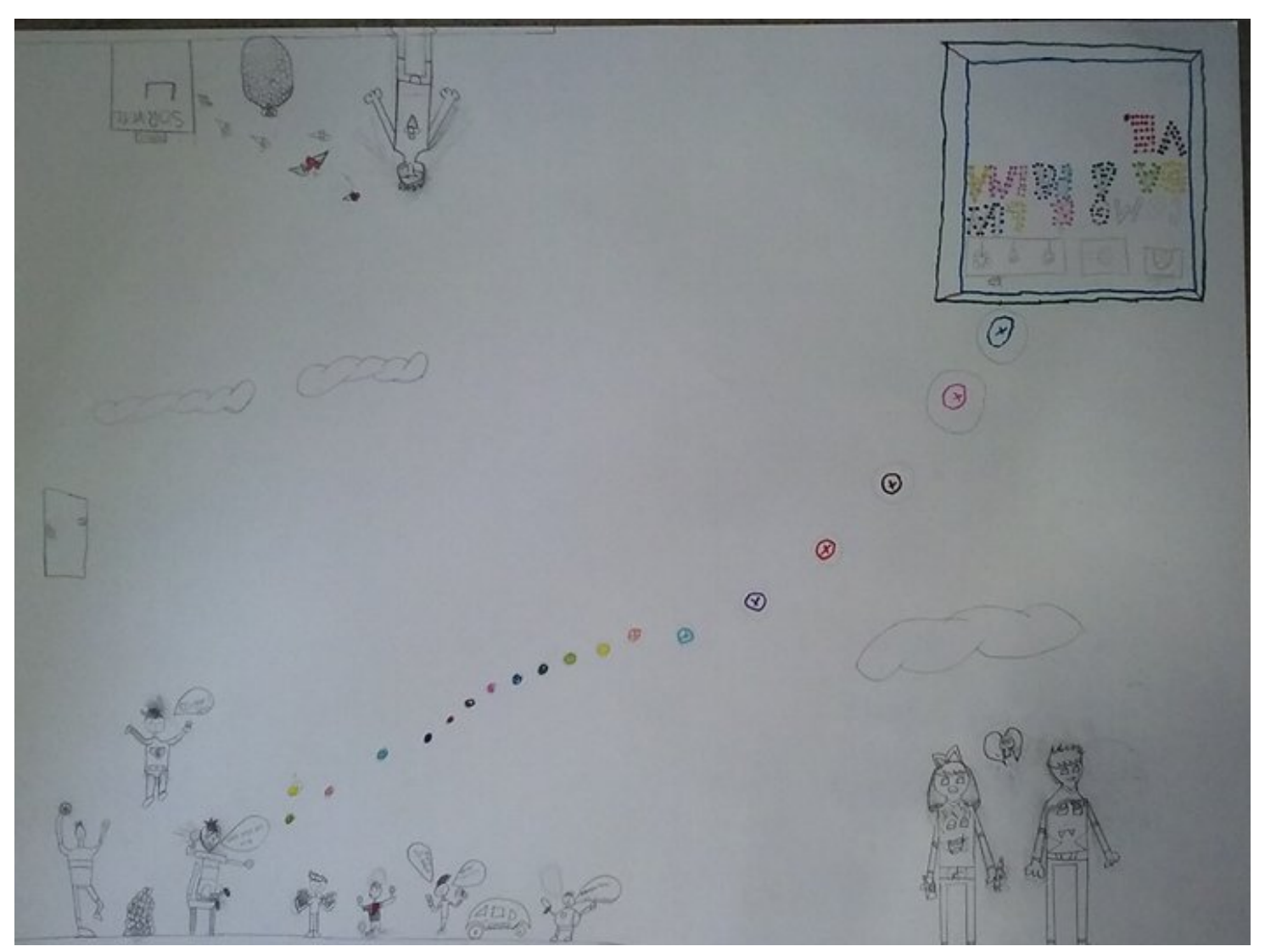

Imagem 3 - "Ui, nem vi!"

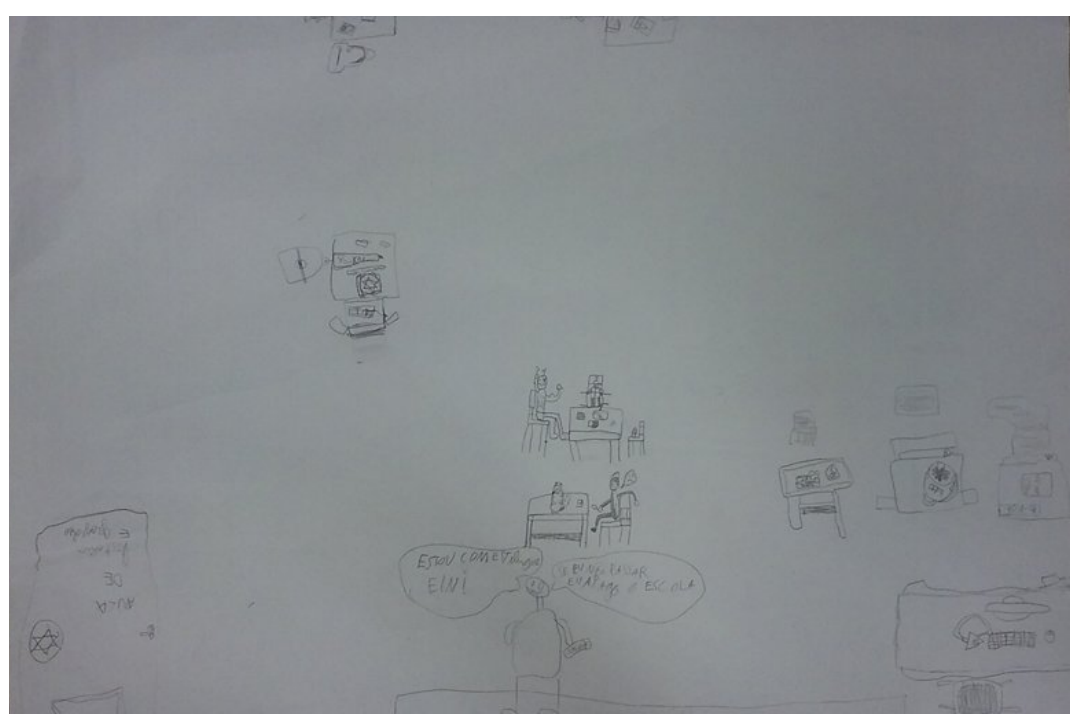

Imagem 4 - "Vou apagar a escola" 


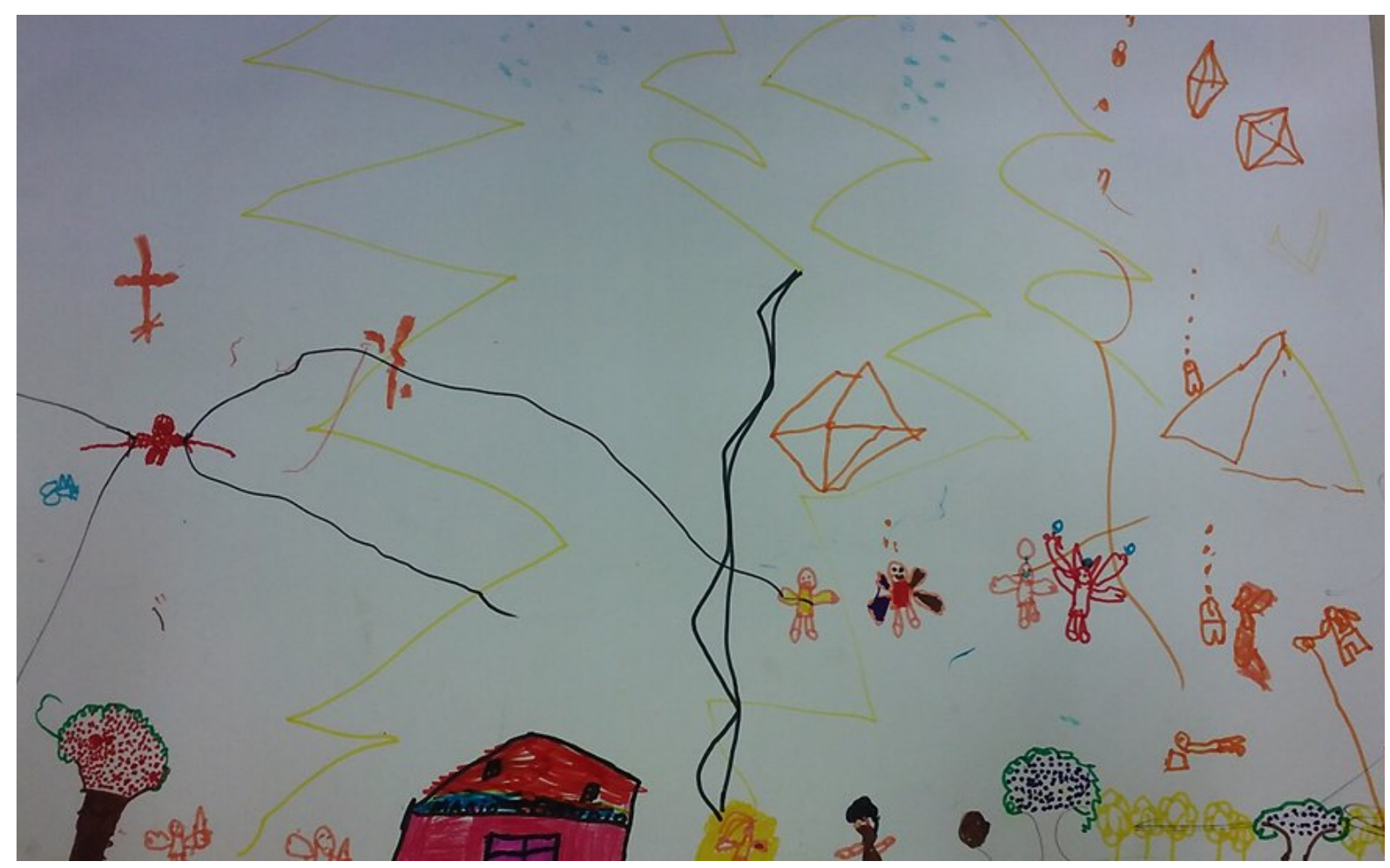

Imagem 5 - Super-heróis e super-poderes

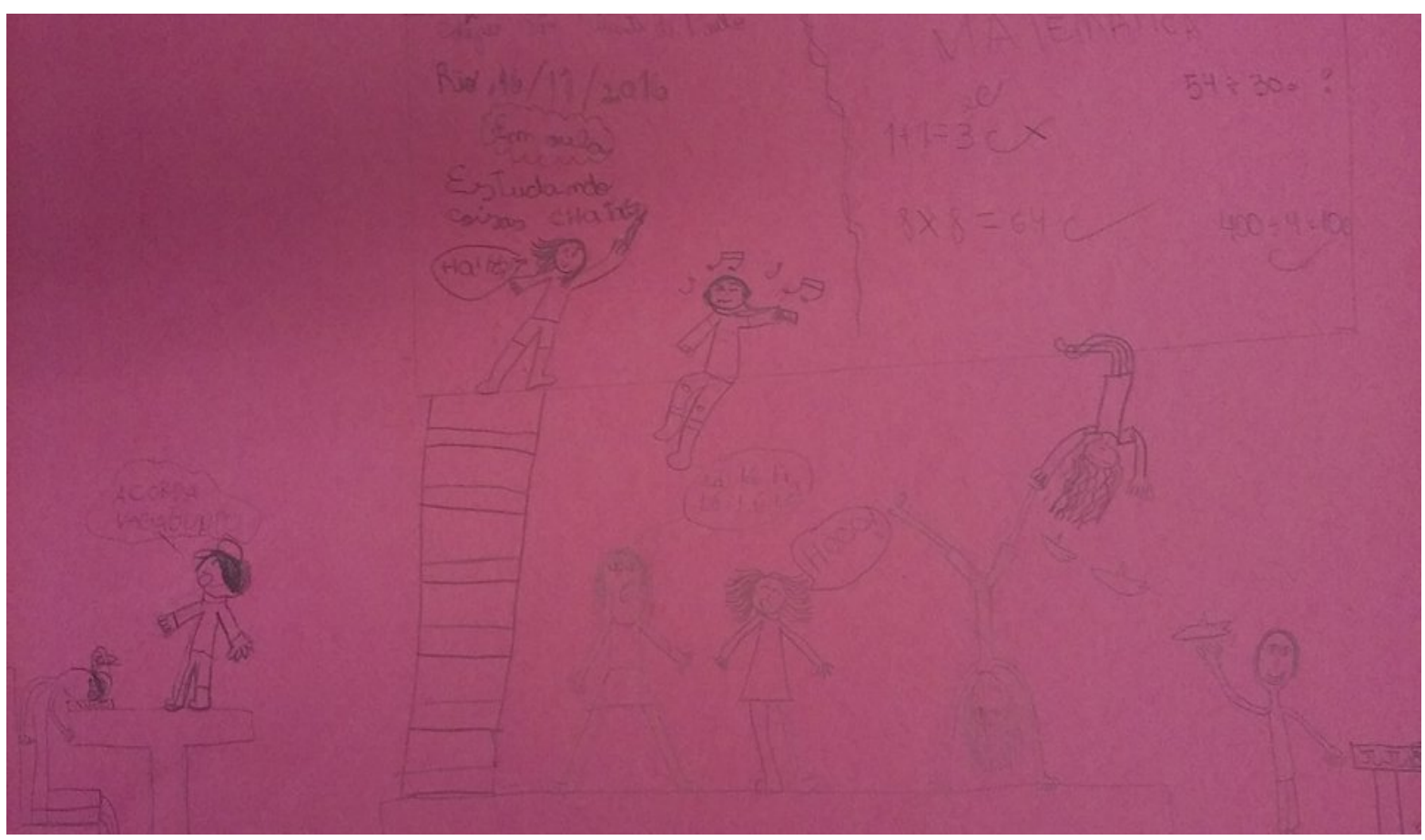

Imagem 6 - "Estudando coisas chatas" (e fazendo piruetas). 
Além valorização tanto da brincadeira em geral quanto da ideia de bagunça é possível notar a afirmação de ações que logram atingir o outro. É interessante notar certo prazer na tal "invasão" na Imagem 4, assim como da busca por apagar a escola, ameaçar ela seja com apagador, borracha ou estilingue. Vemos que na situação fantasiosa de apagar a escola parece haver uma espécie de arma, ferramenta que possibilita, na brincadeira, reagir e negociar de forma mais horizontal as imposições escolares - no caso, o repetir de ano. No caso do parkour, trazido acima, e outras brincadeiras observadas (guerras de frutas e brincadeira coletiva de queda de braço, por exemplo, são algumas brincadeiras que puderam ser observadas na entrada da escola com extrema vivacidade) vemos a possibilidade de recriar os sentidos usuais de objetos como cadeiras e mesas assim como do alimento, trazendo à cena a criança como cocriadora da realidade, co-criação que a princípio se entende distante e dificultosa no espaço escolar. É possível pensar que com este desenho-brincadeira estes podem se tornar, como aponta Winnicott acerca de brincadeira, "mestre e artífice de cada acontecimento que o afeta e que, inicialmente, não eram de sua autoria” (Maciel, 2013).

Quanto ao riso e o humor, é interessante notar as colocações de Bergson (1983), que aponta que este pode ter função de denunciar tudo aquilo que é da ordem do rígido, do automatizado, do inconsciente; neste caso se trata de um humor espontâneo, louco e barulhento, que expõe de forma brusca, quase violenta, tal rigidez. Assim, entendemos que possibilitaria também uma forma de inserção e co-criação da realidade que se apresenta. Mesmo que se observe que nem sempre o riso se dê de maneira crítica e mobilizadora $^{5}$, por vezes o que parece se colocar em cena - no humor que envolve provocações, escatalogias e ações em geral que surpreendem e rompem bruscamente com o contexto escolar - é o descentramento dos sentidos escolares oficias.

Muitos tem aspecto cansado, de saco cheio ou muito agitado. Em um momento um sai de sala e o outro sai depois e diz "ele tá armado, tia” [“como assim?!”] “armado ué, não sabe o que é armado não?”. Parece gostar de me ver temerosa e ri bastante, parece haver certa

\footnotetext{
${ }^{5}$ Ressalta-se aqui as colocações de Lipovetsky (2009) acerca do humor na contemporaneidade, passando este a ter cada vez menos função de crítica e cada vez mais ligado a indiferença, desdramatização e apaziguamento da tensão nas relações.
} 
agressividade nesta provocação. Entendo, então, que é uma arma feita de papel (dobrado). (Trecho do diário de campo)

\subsubsection{A brincadeira que esbarra e afeta os outros}

Se tais formas de ação carregam diversos modos de potencial afetamento daqueles que estão em seu entorno, isso inclui frequentemente o mal-estar. Mal-estar que se dá não apenas em relação aos professores, mas também aos colegas e que varia consideravelmente incluindo desde ofensas e agressões mais direcionadas até o incômodo mais disperso do professor e dos colegas com a bagunça. Cabe mencionar aqui também que, de forma surpreendente, notou-se que conflitos ligados a ofensas também foram frequentemente trazidos nos desenhos associados a ideia de gracinha; isso ficou claro pela maneira que muitas vezes as crianças se mostravam confusas ao escutar a proposta e discutiam entre si se se trataria de uma situação de briga ou de brincadeira. Assim, se compreendeu que a ideia de gracinha possui para estas crianças também sentido de provocações, zoações, ofensas, piadas ofensivas, implicâncias.

Quanto à bagunça propriamente dita, vemos a maneira que esta parece atingir os professores de forma profunda; algo que ficou claro nos desenhos e no contato com as crianças mas também em conversas com os próprios professores e nos registros de ocorrência. Em um dos registros, por exemplo, vemos claramente o incômodo expresso pelo professor: "L. tem a pavorosa mania de dar gritos agudos quando algo a desagrada".

Já nas brincadeiras entre pares, notaram-se aspectos de mal-estar que se referem à exclusão, à implicância, ofensa e brigas. Ressalta-se, ainda, como dito, o mal-estar entre pares justamente pelo incômodo com a bagunça e a brincadeira excessiva do outro.

Para além do mal-estar resultante das brigas, ofensas, provocações, humilhações, exclusões direcionadas e intencionais - que pôde ser observado em diversos momentos - destacou-se de forma mais generalizada o mal-estar ligado à ideia da brincadeira "que esbarra" no outro, algo que não é intencional nem direcionado. Neste sentido, interessa aqui a percepção que a brincadeira parece facilmente escapar dos limites dos indivíduos envolvidos ou da intenção inicial. Este caso é ilustrado de forma bastante representativa em alguns desenhos que retratam uma bolinha de papel ou outro objeto caindo no 
professor (ou diretor, como vemos na Imagem 7), levando os colegas a muitas risadas. De outra forma, vemos também a brincadeira escapar de sua intenção inicial com os relatos frequentes de situações de brincadeiras que viraram brigas, por machucar ou irritar o colega, como vemos nos trechos abaixo.

Passo novamente pela sala e alguns meninos estão brincando e dois estão brigando, dando "gravata" um no outro, se jogando no chão. Eu digo que não dá assim, que eu teria que chamar a professora pois não posso me responsabilizar por brigas. Ai eles param e dizem "estamos só brincando tia”. Estavam rindo. (Trecho do diário de campo)

(...) sobre a frase da gracinha, um menino diz: "já sei! Deve ter sido porque na bagunça e na correria na aula, devem ter mexido ou deixado cair coisas do outro e ai dá briga”. Então quando pergunto que o que acontece "é que é todo mundo fica correndo e a professora pede pra parar e todo mundo ri”... (Trecho do diário de campo)

(...) pergunto como acontece a briga e M. explica mostrando na amiga que vai brincar de alisar o cabelo dela e acaba puxando; ela dá um soquinho e por aí vai. Outros concordam e me mostram "olha tia eu dou logo um tapão...". (Trecho do diário de campo)

Tanto como nas interações predominantemente físicas e humorísticas, estas aqui se mostraram como indicando fronteiras sutis entre aquilo que entendemos como briga ou brincadeira. Cruz e Carvalho (2006) observam o lúdico e o agressivo se expressarem simultaneamente através dos conflitos. Aqui, observamos que mesmo quando não há conflitos aparentemente, a interação física se assemelha à briga: a intensidade e a forma do contato com o outro é facilmente interpretada como briga, com cutucadas, "gravatas", tapas, beliscões, empurrões, puxões de cabelo, corre-corre, derrubar cadeiras etc.

$\mathrm{Na}$ imagem 8, abaixo, vemos que há um menino em cima do outro, sem blusa, levando um beliscão ou algo do tipo de um terceiro. Ao longe, um outro menino observa e dá uma risada. Os olhos do que está embaixo estão revirados e a língua pra fora, o que parece remeter a diversão, brincadeira. Ao conversar com o grupo, explicam que aquele que pede para calarem a boca faz isso por querer silêncio, pois os outros 
estariam bagunçando. É neste sentido, como dito, que vemos frequentemente a bagunça também como brincadeira que "esbarra" no outro, na medida em que incomoda intensamente tanto o professor - que tem sua aula atrapalhada - quanto os colegas de turma.

Este incomodo frequentemente é associado na fala deles ao sofrimento do professor, retratado em desenhos em que este aparece chorando, gritando com a turma ou com expressão de tristeza, como vemos na Imagem 9. Aqui é fundamental observar que este incômodo foi colocado de forma ambígua e fluida pelos alunos, alternando entre o pesar pela fragilização do professor e entre a atratividade do riso e da interação entre pares. Esta tensão é simbolizada na ideia de "Nem todo mundo riu...", fala colocada por alguns em contraponto àquela mais comum que afirma que todos riram em determinada situação.

Além disso, alguns retrataram e abordaram mais diretamente esta dificuldade entre pares relatando acerca de quando gritam uns para os outros "silêncio!" sem parar. Explicam que às vezes os próprios gritos de silêncio viram um barulho sem fim. Quando perguntados na oficina acerca do tema as falas muitas vezes eram ambíguas e entrecortadas, expondo grande dificuldade de tratar do tema. Na imagem 10 vemos um desenho que retrata a complexidade desta situação: neste, vêem-se elementos bastante diversos, que constroem um cenário que parece expor diversidade e fluidez em relação à bagunça. As palavras espalhadas no desenho (como falas das diferentes crianças na turma) dizem: "Tenham mais respeito pela prof! / Podem parar já! / Pora favor parem! / \#semdever / hahaha! / kkkkkk / que desrespeito!! / eu quero estudar!" Três das crianças desenhadas tem uma expressão de raiva ou incômodo, são aquelas que gritam sobre o desrespeito e pedem que parem. Por outro lado, além dos outros estarem sorrindo, o ambiente em geral expressa prazer e descontração, com símbolos musicais e um posicionamento bastante livre dos corpos pelo espaço. 


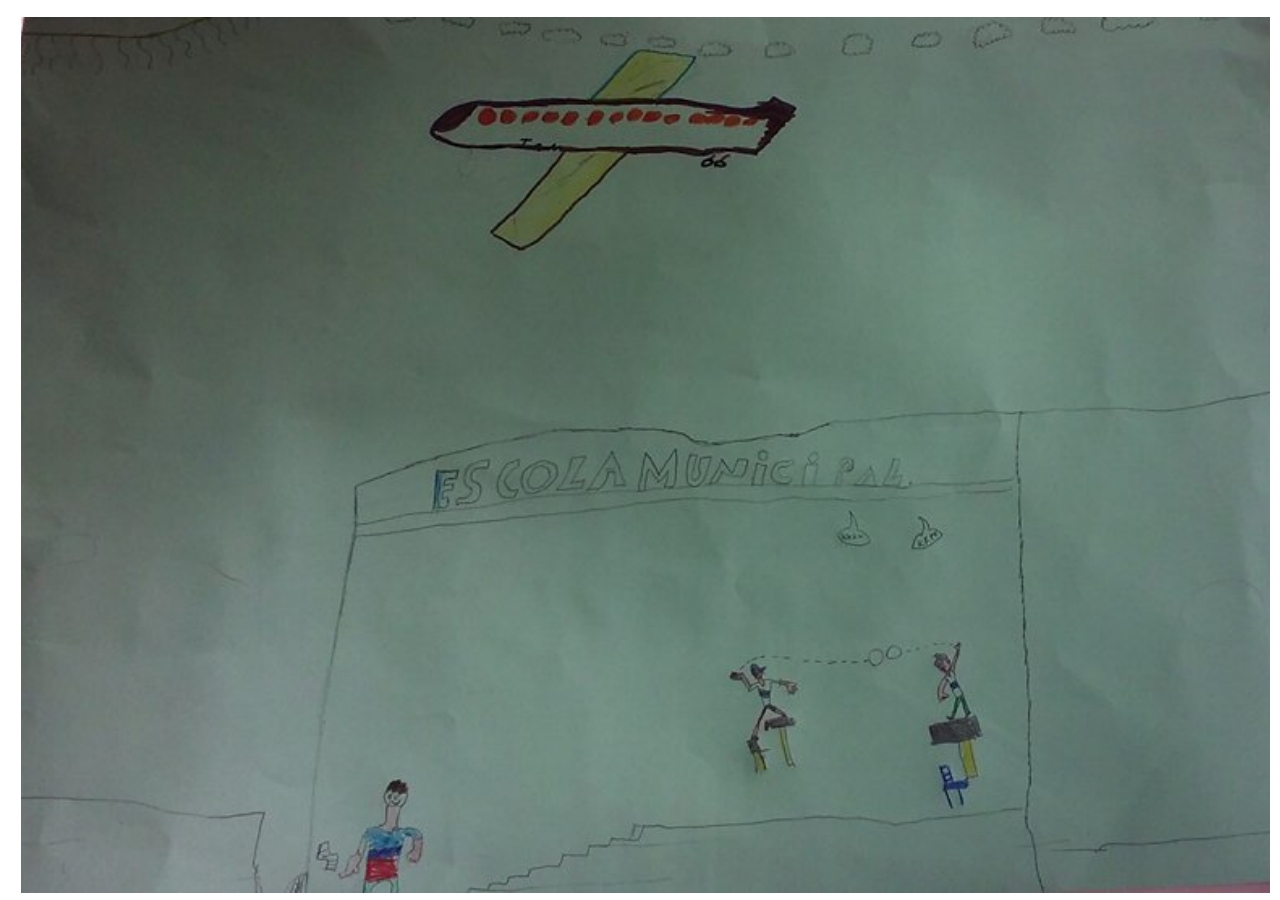

Imagem 7 - Guerrinha que esbarra no professor

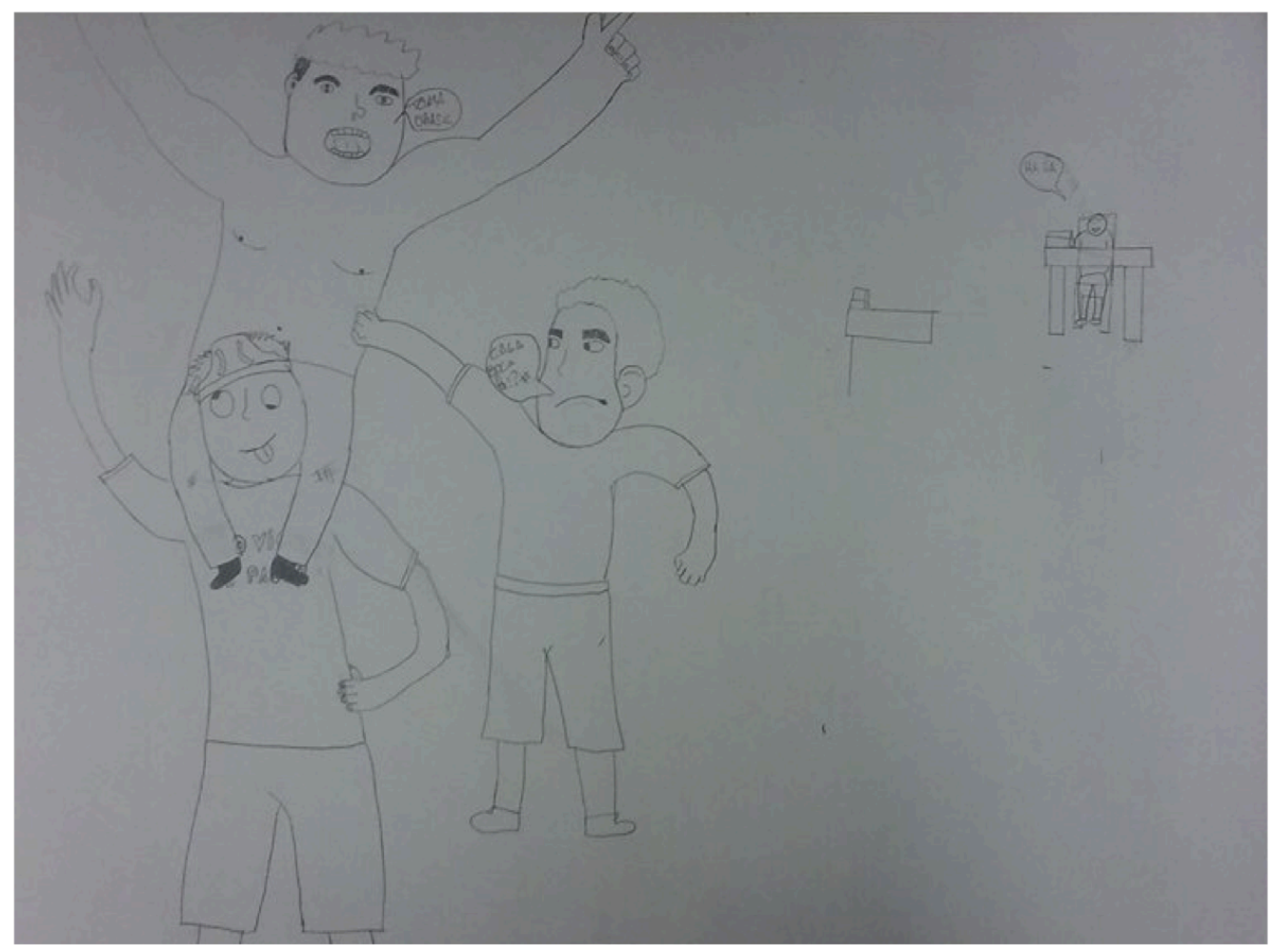

Imagem 8 - "Cala a Boca" 


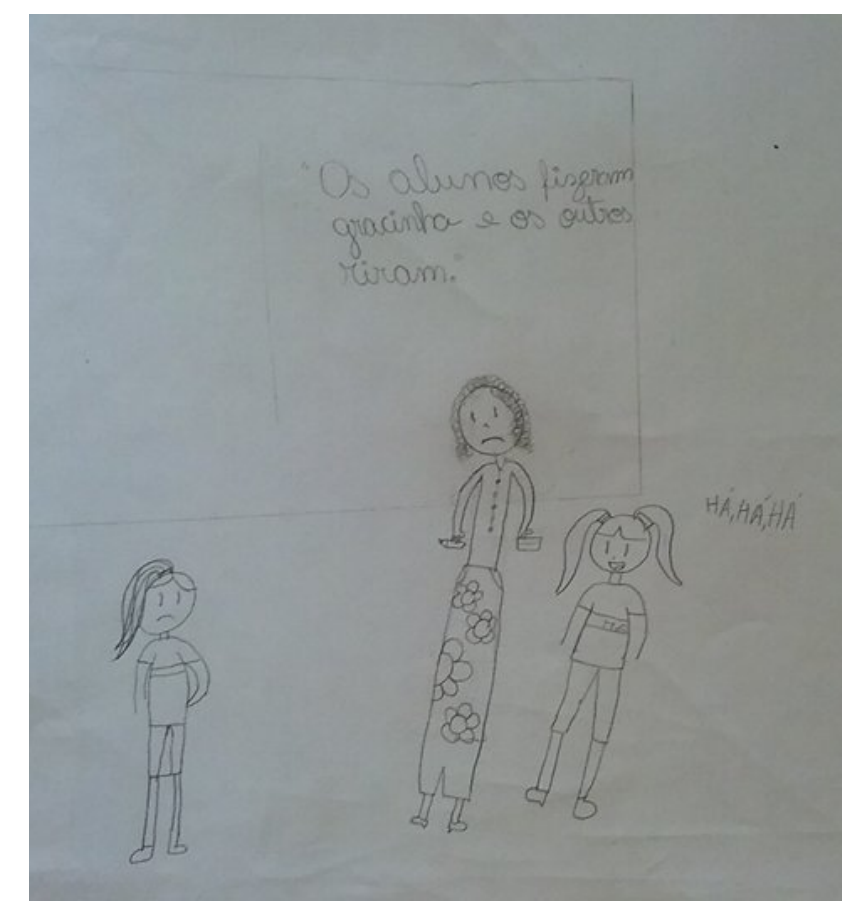

Imagem 9 - Professora triste

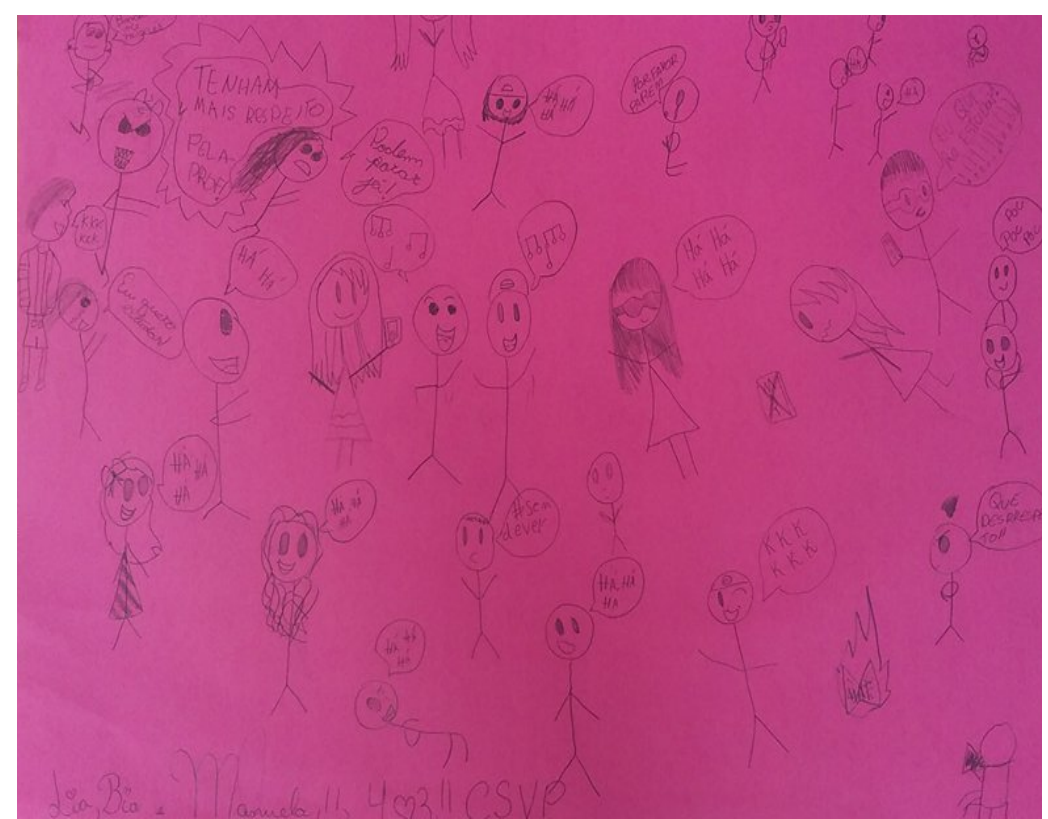

Imagem 10 - "Tenham mais respeito pela prof! / \#semdever / eu quero estudar"

Podemos pensar, neste sentido, na ideia de brincadeira que esbarra no professor a partir da percepção de que as brincadeiras observadas em geral se davam sem limites estabelecidos a priori, tanto em relação a quem participa destas quanto ao que esta pode envolver. Como mencionado, ressaltamos aqui a percepção da brincadeira como podendo conter esta expansividade que, intencionalmente ou não, atinge o outro de 
variadas formas. Neste contexto, podemos notar que para alguns é relatada de forma tensa a vivência em princípio contraditória de "quase explodir de rir" e, ao mesmo tempo, sentir-se mal com a bagunça. Isso parece indicar que neste casos mantém-se a possibilidade de se preocupar com a professora, de não ser indiferente às suas expressões, e ao mesmo tempo de manter a capacidade de ação criativa e espontânea ${ }^{6}$. Como podemos imaginar, entretanto, não é de maneira simples que crianças e os educadores podem lidar e elaborar conjuntamente tais impasses que se apresentam.

\section{Considerações finais}

Em uma análise geral, destaca-se aqui a percepção de que as crianças logram, de diversas maneiras, em modificar o cotidiano escolar. As ações "fora de hora" mostram um pouco da maneira como as crianças participam da criação de seus modos de estar na escola, atuando em atividades não previstas e não esperadas neste contexto mas que parecem representar uma parte importante do cotidiano de todos envolvidos. Mesmo que de forma indireta, as crianças estão a todo momento afetando o seu entorno com estas ações e experienciando os efeitos destas de diversos modos. As brincadeiras humorísticas em sala de aula, assim como as interações físicas, rompem ou modificam significativamente com a maneira esperada e demandada de realização das tarefas escolares (fazendo com que estas se deem com muito mais lentidão, por exemplo, entremeadas por brincadeiras e interações). As brincadeiras, para além de representarem formas de incômodo e contestação, representam também formas de agir no mundo, impondo (permitindo expressar espontaneamente) determinadas formas de interação e fruição que divergem do esperado. Com a brincadeira é possível sentirem-se (e serem) co-criadoras neste espaço, seja re-criando o espaço da sala de aula, os objetos e as relações nesta realidade escolar que a princípio se entende tão distante da ação transformadora da criança.

Pensar acerca das brincadeiras "fora de hora" na escola e observar um pouco da maneira que estas se dão em sala de aula nos leva a refletir sobre o lugar que ocupa no espaço escolar tudo aquilo que está à margem das tarefas escolares "oficiais". Se toda demanda de obediência hoje é passível de ser questionada, como exposto anteriormente,

\footnotetext{
${ }^{6} \mathrm{Em}$ outros casos, alguns falam com regozijo e certo prazer a possibilidade imaginária ou real dos professores se afetarem com suas ações, com incômodos diversos. Aqui, fica latente o antagonismo entre professores e alunos que se apresenta especialmente em algumas turmas, tema que não foi enfocado neste trabalho.
} 
as ações de crianças frequentemente expõem interesses, desejos - e talvez possamos dizer, necessidades - acerca de diversos outros aspectos da convivência escolar. Neste sentido, optamos por mencionar certas ações das crianças não necessariamente como desinteresse no que se refere ao ensino e àquilo que lhes é demandado, mas como interesse em outras formas de estar na escola, que coexistem com aquelas "oficiais". Desta maneira, este tipo de ação pode ser entendido como evidenciando a falta de sentido não de estar na escola, mas de estar nesta apenas da maneira exata esperada pelos educadores. Assim, tais ações mostram a maneira como as crianças participam da criação de seus modos de estar na escola, atuando em atividades não previstas e não esperadas neste contexto, mas que parecem representar uma parte importante do cotidiano de todos envolvidos.

Estas ações acabam por tornar visível, entretanto, a enorme dificuldade de diálogo e formulação de acordos e sentidos comuns entre todos na escola. Tais efeitos no ambiente, que a brincadeira forja e expõe, são parte da complexa trama relacional do convívio na escola; importa compreender que tais efeitos não podem ser controlados de antemão, mas devem ser acompanhados e elaborados coletivamente permanentemente, de maneira que se inclua neste processo a escuta da criança. Ressalta-se que tanto as brincadeiras espontâneas quanto os conflitos e tensões mostram ser pouco aprofundados no cotidiano escolar oficial. Resta, assim, pensar na possibilidade de uma escola que possa ter uma "escuta" - não apenas com a audição, como aponta Sarmento (2005) mas com o olhar, atentar e lidar - para aquilo que é expressado e afirmado pelos alunos em suas formas e sentidos mais amplos.

\section{Referências Bibliográficas}

Arendt, Hannah. (1961) Crise na Educação. In: Entre o passado e o futuro. New York: Viking Press.

Bergson, Henri. (1983) O riso: ensaio sobre a significação do cômico. Rio de Janeiro: Zahar Editores.

Aquino, Julio Groppa. (2005) Jovens "indisciplinados" na escola: quem são? Como agem?.. In: SIMPOSIO INTERNACIONAL DO ADOLESCENTE, 1., São Paulo. . Disponível: 
$<$ http://www.proceedings.scielo.br/scielo.php?script=sci_arttext\&pid=MSC0000 000082005000100002\&lng=en\&nrm=abn>. Acess on: 03 Aug.

Birman, Joel. (2008) Criatividade e sublimação em psicanálise. Psicologia Clínica, v. 20, n. 1, p. 11-26.

Castro, Lucia Rabello. (2013) O futuro da infância e outros escritos. Rio de Janeiro: 7Letras. . (2001) Da invisibilidade à ação: crianças e jovens na construção da cultura. In: CASTRO, L. R. de (org) Crianças e jovens na construção da cultura. Rio de Janeiro: Editora Nau.

. (2012) Entre a subordinação e a opressão: os jovens e as vicissitudes da resistência na escola, p. 63-98. In: CASTRO et al. Juventudes e a experiência política no contemporâneo. Rio de Janeiro: Contra Capa.

Castro, L. R. de et al. (2010) Falatório: participação e democracia na escola. Rio de Janeiro: Contra Capa.350p.

Cruz, Tânia Mara; Carvalho, Marília Pinto de. (2006) Jogos de gênero: o recreio numa escola de ensino fundamental. Cadernos Pagu, v. 26, p. 113-143.

Devine, Dympna. (2002) Children's citizenship and the structuring of adult-child relations in the primary school. Childhood, v. 9, n. 3, p. 303-320.

Gullestad, Marianne. (1996) From obedience to negotiation: dilemmas in the transmission of values between the generations in Norway. Journal of the Royal Anthropological Institute v. 2, n.1, p. 25-42.

Guirado, Marlene. (1996) Poder indisciplina: os surpreendentes rumos da relação de poder. p. 57-71. In: Indisciplina na escola: alternativas teóricas e práticas. São Paulo: Summus.

Lejarraga, Ana Lila. (2012) O amor em Winnicott. Rio de Janeiro: Garamond/Faperj. $156 \mathrm{p}$.

Lipovetsky, Gilles. (2009) A era do vazio: ensaio sobre o indivíduo contemporâneo. São Paulo: Manole. 
Maciel, Maria Regina. (2013) Psicanálise e Educação: do barulho à batucada. Cadernos de psicanálise, Rio de Janeiro, v. 35, n. 28, p. 169-181.

Maciel, Maria Regina. (2016) Psicanálise e educação. Editora Casa do Psicólogo, 160 p.

Marsh, Peter et al. (1973) The rules of disorder. London: Routledge \& Kegan Paul.

Raby, Rebecca. (2005) What is Resistance? Journal of Youth Studies, v. 8, n. 2, p. 151171.

Renaut, Alain. (2005) O fim da autoridade. Lisboa: Instituto Piaget.

Prout, Alan. (2000) The body, childhood and society. Palgrave Macmillan UK.

Sarmento, Manuel Jacinto. (2005) Gerações e alteridade: interrogações a partir da sociologia da infância. Educação e Sociedade, Campinas, v. 26, n 91, Maio/Ago., 2005.

Simpson, Brenda. (2000) The Body as a Site of Contestation in School. In: PROUT, Alan. The body, childhood and society. Palgrave Macmillan UK, p.60.

Salgado, Raquel Gonçalves; Silva, Maira Regina Souza. (2010) EU, TU, ELES: A amizade como passaporte para brincar. Curriculo sem Fronteiras, v. 10, n. 2, p. $55-65$.

Sultana, Ronald. (1989 Transition education, student contestation and the production of meaning: possibilities and limitations of resistance theories. British Journal of Sociology of Education, v. 10, n.3, p. 287-309, 1989.

Thornberg, Robert. (2008) 'It's Not Fair!'-Voicing Pupils' Criticisms of School Rules. Children \& Society, v. 22, p. 418-428.

Winnicott, D W. (1975) O brincar \& a realidade. Rio de Janeiro: Imago. . (1999) Privação e delinqüência. São Paulo: Martins Fontes. - (1983) O ambiente e os processos de maturação: estudos sobre a teoria do desenvolvimento emocional. Porto Alegre: Artes Médicas. 